Article

\title{
Decoding the XXI Century's Marketing Shift: An Agency Theory Framework
}

\author{
Gandolfo Dominici ${ }^{1,2, *}$ and Maurice Yolles ${ }^{3}$ \\ 1 Professor of Marketing, Department SEAS, Polythecnic School, University of Palermo, Palermo 90128, Italy \\ 2 Scientific Director, Business Systems Laboratory, Avellino 83100, Italy \\ 3 Professor Emeritus of Management Systems at Liverpool John Moores University, Liverpool L3 5UA, UK; \\ prof.m.yolles@gmail.com \\ * Correspondence: gandolfo.dominici@libero.it or gandolfodominici@yahoo.com
}

Academic Editor: Ockie Bosch

Received: 12 August 2016; Accepted: 7 November 2016; Published: 15 November 2016

\begin{abstract}
Since the beginning of the XXI century, marketing theory has moved through a series of epistemological shifts from modern positivism to postmodern constructivism. This has resulted in a series of changes to the main concepts of "traditional" marketing such as: market, product, customer, and value. These shifts can be better viewed under a social cybernetics approach such as agency theory. This is because there is now a view that the linear concept of value creation needs to give way to the more complex process of value cocreation, where value is created collectively. Agency theory is one approach that is able to shed light on how customers and providers are able to recursively create collective value during interaction in a market. The theoretical framework provided here is able to provide improved understanding of the interactions betfween (and among) customers and providers in the value cocreation process. In this theory, value cocreation is depicted as an interactive process between a set of "living system" agencies (providers and customers) in a given market arena. The framework can be an effective tool for the managers involved in marketing to contribute to providers' policies by supplying a clearer portrait of the systemic relations involved in the value cocreation dynamics.
\end{abstract}

Keywords: value cocreation; agency theory; market; customer; product; eigenform; marketing theory

\section{Introduction}

A fundamental paradigm shift occurred in XXI century marketing, moving it from modern positivism to postmodern constructivism [1-5]. This has occurred as a conceptual shift that redefines the nature of customer, value creation, product, and market, and their relationship.

Starting in the 1990s and continuing into the new millennium, the issue of value cocreation had started to achieve interest in the marketing literature, overcoming the established vision that value for customers was the mere output of firms' manufacturing processes [6]. The discussion on value cocreation in the domain of Service Dominant Logic has been lost in thought in the discussion about what service does for customers [6]. Nevertheless, value cocreation is a complex process that cannot be reduced to a simple or even complicated pattern, but that requires a systemic view to better understand its complexity.

The two main areas of value cocreation (i.e., consumption and provision) are not just interdependent on each other, but are generated by a multitude of internal and interconnected agents and processes.

Grönroos et al. [7] has noted that the concept of co-creation has been portrayed in at least three different ways in the main literature: (1) according to Service Dominant Logic (SDL) "value is always cocreated"; (2) for Service Logic (SL) "value is created only in collaborative, interactive, and dialogical 
processes"; (3) for Customer Dominant Logic (CDL) "value is co-created when it is driven by mutual intentions" [7]. All these three perspectives give some elements that can be useful to understand the value cocreation process. Furthermore, it arises that from the above-mentioned approaches, value cocreation may occur in different contexts: it can be intentional value co-creation driven by the provider or by the customer, or it may be spontaneous [7].

This paper derives from the realisation that there is currently no published exhaustive modeling framework available in the marketing literature that fully represents the complex process of value cocreation, including all the above-mentioned perspective and cases. In this paper, we offer one that is able to do this. It is called agency theory, and it is connected with social cybernetics and "living systems" theory. Agency Theory is unique in its ability to explicitly model complex contexts in which control and communications are central components, as in the case of modern day considerations of marketing processes. This is due to its ability to represent those contexts through generic structures that can be used to fully signify their strategic and cultural attributes and ultimately to anticipate future behaviors. Agency is an entity that is an active organism capable of having desires, making plans, carrying out actions [8], communicating with other agencies, and is able to adapt in changing environments. Customers are active co-creators of value through communication with other customers. Customers engage in conversations with other customers both face to face and by sharing their experiences, thoughts, and feelings on social media, thus co-defining the symbolic meaning of brands and products. This happens today mainly through interactions on Social media, where the value co-creation process is activated by customer-to-customer communication. It can therefore be used to represent customers, providers, and the complex interactions between them that occur within social media, and to explain the dynamics of value cocreation. The contribution that agency theory makes here is to facilitate the discussion of the marketing value cocreation process, and in so doing, to provide insight to the nature of the paradigm shift and the conceptual change that accompany this through revised conceptual meanings of customer, market, and product, and the relationships between them. Furthermore, mainstream marketing approaches tend to adopt linear models that see the creation of value in the market as (at best) a mere cumulative sum of all the individual values. In contrast, agency theory takes the view that value cocreation is the result of complex social communication taking place in a lifeworld (defined through the thematic communications that occur among a network of participants that offers a potential for common understanding) where meanings are relative to agencies (producers and customers), and as these are communicated between each other a process of symbolic sense negotiation develops. We further show how agency theory can be an effective approach to decode the inner mechanism of value cocreation. Our analysis can be a starting point for the development of more accurate managerial models capable of steering the value cocreation dynamics.

Based on systemic analysis of the value cocreation process through an agency theory framework, the purpose of the present paper is to explain the strategic and cultural attributes involved, and their intra and inter-systemic relations.

After an introduction on the main concepts of agency theory (Section 2), we shall explain the nature of the main shifts in marketing theory, and then create a narrative through agency theory to explain the complex process of value cocreation (Section 3). We then conclude with some reflections and suggestions for further research.

\section{Theoretical Background of Agency Theory}

It has been said that agency is an entity that has the capacity, condition, or state of acting or of exerting power. Set within a theoretical web, agency theory is concerned with the relationship between two or more parties who may act as agencies to each other, and is concerned with the determination of the general structure that enables them to be agencies, and the interactive relationships between them. The general structure associated with agency here refers to its substructure and superstructure. Agency substructure is a living system metamodel: an eleboration of the concept of autopoiesis (self-production) developed by Maturana and Varela [9], and which arises with Schwarz [10-12]) 
who's extension was to include autogenesis (self-creation). A living system is an open self-organizing system that interacts with its environment which it internalises through processes of autopoiesis and autogenesis-networks of processes that manifest forms of information, energy, and matter as appropriate and determined by context that will contribute to the determination of how complex human system processes develop, facilitating the emergence of collective interactions-in this case in a marketing arena resulting in individual or collective eigenbehaviours (See section 3.3). The importance of living system theory is expressed by Vancouver ([8], p.165) who tells us that it can " .. provide a framework for describing the micro (i.e., human), macro (i.e., social organisations), and meso (i.e., interaction between the two) levels of the field without relying on reductionism or reification. The more parsimoniously it can do this, the better $[13,14]$. Second, it should provide a model of the major processes of dynamic interaction between individuals, situations, and behaviour to address the major phenomenon of the field like behaviour, cognition, and affect [15]. Finally, it should provide researchers with research ideas [14]."

Vancouver [8] continues by saying that living systems theory entails the proposition that living systems can maintain regularity despite irregularity in their environments. This regularity is accomplished by comparing current or anticipated states with internally represented desired states and converting any difference into actions that will enable the maintenance of small differences. Vancouver further notes that in living systems theory, influences emerge from evolutionary and biological to sociological and economic processes.

Cocreation is an emergent phenomenon deriving from the self-organization of living systems. Self-organization is a property of complex systems, composed of active elements whose system of interactions serves for the exchange of matter, energy, and information among their parts and with their context. Self-organization does not imply an external "shaper" of the system; rather a living system continuously organizes and re-organizes its structure and function spontaneously by itself [16].

To capture such attributes, agency theory (as presented here) adopts the concept of autopoiesis [9], which Mingers [17] notes refers to systems that are self-producing or self-constructing, and this is indicative of certain properties of living as opposed to non-living entities. This modelling approach has been enlarged to encompass attributes of cognition and communication, leading to what a form of what is known as second-order cybernetics [17]. Schwarz [11] developed a more comprehensive general theory of living systems in which autopoiesis constitutes one part, the other being autogenesis or self-creation. Yolles [18] has elaborated this into a knowledge-based theory that has its seat in the theory of anticipation. When living systems theory is set within the context of agency learning, concepts by Piaget [19] can be adopted so that autogenesis and autopoiesis are represented through forms of process intelligence.

Agency theory is not new. Bandura [15] highlights three different formulations for it. These are the economic agency, the emergent interactive agency, and the autonomous agency. The economic agency is seen as an internal instrumentality through which external influences operate mechanistically on action; this approach eliminates properties of motivation, self-reflection, self-reaction, creativity, and self-direction. Such attributes of an agency imply that internal events are a reflection of the impact of external environments from which causal attributes are ignored, and the self-system is merely a repository and conduit for environmental forces, or in other words a black box, and as such self-influences do not exist. This approach is typical where investigations that occur involve more general questions of incomplete information and risk sharing. It is also concerned with analysing and resolving problems that occur in agency relationships. The theory assumes that a principle agent delegates authority to other agents, but there are issues because strategic attributes such as goals and information about capacities and activities vary. The approach focuses on the ways that principals try to address the control problem by selecting certain types of agents and certain forms of monitoring of their actions, and by using economic incentives. This agency theory, has limitations because it does not consider intrinsic agency imperatives.

The emergent interactive agency is an approach adopted by Bandura [15] to explore social cognition. Here the agency makes causal contributions to its own motivations and actions using 
"reciprocal causation." The latter adopts attributes of self-regulation and control, and action, cognition, affect, and other personal, environmental, and interactive factors are involved. In reference to the autonomous agency, Bandura [15] makes a fundamental error by misunderstanding that there is a distinction between an autonomous and an isolated agency, and so dismisses this without much further regard saying that no real agency is autonomous (meaning isolated) from interaction with others. The term autonomous is normally used within the context of interactive environments, where an autonomous system is self-directed while also being influenced by its environment. It may additionally have its own immanent dynamics that impact on the way it interacts. It is a core concept in Beer's [20] Management Cybernetics. The emergent interactive agency is fundamental to its existence.

Yoon [21] notes that Bandura's approach also refers to the capacity of the agent to exercise control over the nature and quality of its life, and in doing so operates with four core features: intentionality, forethought, self-reactiveness, and self-reflectiveness. Agencies are also proactive, self-organizing, and self-regulating. They participate in creating their own behaviour and contributing to their life circumstances. An agency also has cognitive functions that may be represented through personality.

Agency theory is a generic "living systems" framework [22-24]. This redefines Bandura's conception of the autonomous system approach. As previously indicated, the concept of a viable living system as adopted here arises with the work of Schwarz [11]. This sits on the foundational work of Miller [25], which reduces the complexity of the structure and organisation of living systems. Miller provides a common framework for analysing the nature, condition, structure, and process of systems at various levels of complexity. This ability to compress complexity has been important to living systems theory. It also sits on the work of Maturana and Varela [9], who were interested in the biological basis of living, and created a generic modelling approach that has the capacity to anticipate future potentials for behaviour.

\section{The Marketing Paradigm Shifts}

\subsection{Customers as "Agencies"}

Originally the customer was seen as a consumer capable of manipulation such that value can be created. This was replaced by one in which customers have perspectives that might vary.

Consider a market space populated by interacting providers and customers. Adapting a definition from Rampen [26], value cocreation arises when customers are able to personalize experiences through a product (during the lifetime of its use) to a level that is best suited to satisfy expectations relating to requirements. This may connect with personality attributes that constitute drivers for the provider that include loyalty and relationship formation. Value cocreation allows customers and a provider to derive greater value from product experiences, which is constituted as new knowledge, higher revenues, and/or improved brand loyalty. The participants in value cocreation (i.e., customers and providers) may also be known as agencies: entities that have the capacity, condition, or state of acting or of exerting power in a market process in connection with some utility that has potential value.

Customers are no longer conceived as just targets that inactively take delivery of stimuli coming from market providers in terms of offerings and communication. Customers play an important and active role in the creation of meaning [27-31]. The market arena is the land of encounters between providers and customers, where customers and providers construct an active, interactive, and dynamic system of sense/meaning through recurrent communication loops [32,33].

\subsection{The New Concept of Value Creation}

The traditional concept (here we refer to the Kotler approach as the most widespread in his Marketing textbooks in the last century) of value creation arises from the connection between the producer and the customer, and centres on the producer as the initiator of the perception of value. Here, the producer sees the customer as an object of attention that can be manipulated into value creation. 
In the early 1980s, Toffler [34] predicted that due to the advances of communication technologies and the consequent enhancement of the relational capabilities between individuals, the dynamics of value creation in the market arena would progressively change. Thus, the traditional marketing logic based on the proposition of value creation applied to clustered targets of customers (that define a segment of the market) is outdated since it makes no contribution to the understanding of the dynamic processes of value cocreation.

Value creation is an outcome of passive customer exposure to product promotion by producers $[35,36]$. The original concept of value creation was a strategic process that provided the intellectual frameworks, conceptual models, and governing ideas that allowed a provider of products (a term which we shall take to include services) to identify opportunities for bringing "value" to consumers and to deliver that value at a profit [37]. It constitutes a one-sided definition that centres on the provider.

In contrast, value cocreation is a dynamic process that results from the thematic behavioural space of rich interactions that constitute a lifeworld involving the exchange of meaning during communication processes that have consequences for agency behaviours.

The concept of value cocreation emerged in the domain of 'service-dominant logic' [38-40] and quickly assumed a key relevance in marketing theory [41,42]. This recognises that value is not exclusively created for customers by providers but for both, and by all the agents in the market arena over the full duration of their dynamic interactions $[43,44]$.

\subsection{Product as an "Eigenform"}

To understand how a product can embody cocreated value, it is necessary to first define the nature of a product. The most common definition comes from Kotler and Armstrong ([45], p. 245): "Anything that can be offered to a market for attention, acquisition, use or consumption that might satisfy a want or need". Therefore, from Kotler and Armstrong's perspective, a product is an asset that comes into the market from an external source and is created by a provider "out there", and is introduced into the market arena for a specific targeted need that should be satisfied. However, is this the case for value cocreation? Is the value of a product something that depends on its creator? Is the value of a product that of a mere "object" that is created and offered by a provider? The response is necessarily no, because value cocreation happens in the market arena as a result of interactions and is not an entity within its environmental marketplace.

Traditionally a "object" is seen as a thing that is out there in a four-dimensional time-space, and is normally perceived as a separate form "out there" and independent of any observer. However, more appropriately, an object is not seen as something outside of the system in an environment that is just perceived by an observer (even where the observer's perspective can be properly formulated [46]). This in turn leads to the question of whether a product (as an object) is the same for all customers, which of course it is not from a constructivism perspective.

For instance, we may reflect on what Jerome Bruner [47] reported on when, in 1924, physicist Werner Heisenberg took a walking tour with Niels Bohr and they came to Kronberg Castle (Kronberg is known to many as the setting of William Shakespeare's famous tragedy Hamlet):

“Isn't it strange how this castle changes as soon as one imagines that Hamlet lived here? As scientists we believe that a castle consists only of stones, and admire the way the architect put them together. The stones, the green roof with its patina, the wood carvings in the church, constitute the whole castle. None of this should be changed by the fact that Hamlet lived here, and yet it is changed completely. Suddenly the walls and the ramparts speak a different language.

[...] Yet all we really know about Hamlet is that his name appears in a thirteenth-century chronicle. [...] But everyone knows the questions Shakespeare had him ask, the human depths he was made to reveal, and so he too had to be found a place on earth, here in Kronberg." ([47], p. 45) 
This can be placed in a marketing context. The battle between VHS and Betamax video tapes resulted in the technically inferior product becoming the standard [48] due to the creation of value. Another explanation is provided by the motorbike industry. Harley Davidson is a valued motorbike brand, though there are similar less expensive machines with better performance. The value of Harley Davidson goes far beyond its value as an object, including many perceived features coming from the history of the brand, the storytelling around it, its communication, and its psychological power that make its performance weaknesses its strong points for its brand supporters. Following Schembri [49], Harley Davidson is a cultified and valued product, the cult sharing an esoteric veneration of the product that has become "a symbol of American freedom, independence and his own status as a regular guy" [50], forming a "subculture of consumption" based on symbolic values [51].

So, value cocreation occurs when an object is seen as something perceived by an observer and socially valued, the perception being fluid and varying through time and space. As such, to understand a flow of perception, it is relevant to study the "processes," though it is of little or no use to analyze the single phenomenon in a single period of time and place.

This interest in observation and process brings us to the notion of eigenform. The German word "eigen" means proper or characteristic. Eigenform means a patterning of the "behaviour of observation", which means instead of taking "observation as a seeing of objects", it is rather a process that has trajectories which unite both the observer and the observed [52]. While it is possible to do without this term, its definition offers a very specific meaning that allows for explanatory brevity. The term was first introduced by Heinz von Foerster [53] and is inextricably linked with second order cybernetics (or cybernetics of the observer) and the circularity of knowledge [46,54]. Von Foerster asserted that familiar objects of our reality can be seen as nothing more than "tokens" for the behaviours of the living system that create stable forms. This conception of objects as symbols or tokens does not deny a primary reality that is the source of these tokens, but to a certain extent to underline the relevance of processes and the role of sense-making in the production of a perception map that leads the behaviours of the individual agencies [46,54]. As Kauffman ([46], p. 6) points out:

"For an observer there are two primary modes of perception: compresence and coalescence. Compresence connotes the coexistence of separate entities together in one including space. Coalescence connotes the one space holding, in perception, the observer and the observed, inseparable in an unbroken wholeness. Coalescence is the constant condition of our awareness. Coalescence is the world taken in simplicity. Compresence is the world taken in apparent multiplicity."

In the compresence mode of perception, objects cannot be separated from actions. According to this view, objects are symbolic entities, involved in a system of interactions from which they take their apparent solidity. The perceptible solidness of external forms is nothing more than a "mirror of the stability of the process by which these forms come into being" ([46] p. 1). Hence, forms are created from the concatenation of actions inside a process and objects are symbols that function as signals for "behaviours" of the dynamics of the processes. This implies that the common objects of our perceived experience (which combine as eigenforms) are the landmarks for agency operations that appear in a marketing area with an agency geography. Eigenforms are created through eigenbehaviour, which has direction and intensity indicated by an eigenvalue. A set of eigenvalues that constitute the dynamics of a value cocreation system is called an eigenvector. These are commonly shared sets of basic values that come from social, cultural, and psychological factors of each agency in the market, and through eigenbehaviour processes, higher level values are created that relate to the product and are referred to as the eigenform. Therefore, cocreated value is not something objectively measurable, but is rather the construction of realities that preserve the circularities of participation in networks of conversations [55]. As such, the cocreation of value within a market is a continuous and dynamic process that needs to be fostered by continuous communication, negotiation, and action of all the agencies in the market arena. Agency theory allows us to analyse the information flows generating eigenvalues $\rightarrow$ eigenvectors $\rightarrow$ eigenbehaviors $\rightarrow$ eigenforms and understand the nature of the value creation process. 
Customers' agencies, in the market arena, build up a "pre-orientation" consisting of preferences regarding the description of existing and/or desired products, and their behaviour interacting with them. These preferences can be seen as "stabilized hypotheses" about the product enabling the customer agency to deal with it; in other words, they are eigenvalues produced by the cognitive system of the observer [56]. This implies that eigenvalues, eigenbehaviours, and eigenforms emerge at different levels as regularities from interactions among agencies that are able to communicate even though they are interacting in a very complex context [56,57]. Of course, these regularities are "fluid" social ties that have no inertia and need to be continuously renegotiated [58]. Therefore, the value of a product relies on the perception of a customer. This perception may be different depending on a number of social, cultural, and psychological variables that may be completely dissimilar when considering different customers and/or the same customers over a different time and space.

Eigenbehaviour is a pattern of behaviour that arises in an agency due to its cultural-cognitive conditions, and as a consequence can be conceived as the system of operations within the cocreation process. Personality theory can be used to anticipate patterns of behaviour [59-62], and hence become a determinant for eigenbehaviour. The direction of development and the implementation of the eigenbehaviour is given by eigenvectors that are the result of eigenvalues. As such, eigenvalues are a determinant of eigenbehaviours that arise from formative agency traits [63-65], including personality traits. Agencies act in the complex context of the market according to eigenbehaviours, that in turn are generated by recursive eigenvalues: this process produces "regularities" (i.e., eigenform) that are tokens that give direction (thereby skirting complexity) of agencies' decision.

\subsection{A New Notion of the Market as an Arena for Agencies}

The traditional conception of "market" can be represented by two distinct characteristics: (1) an aggregation of consumers; and (2) the locus of exchange where providers trade their products in exchange of money with customers [66]. This traditional vision views customers as being isolated from the value creation process, and simply being market objects that have the property of "consumption" that might be elaborated in some way.

In other words, in its original conceptualisation, the market exists through its population of customers (and providers). Customers are exposed to products as "objects of attention" by providers, objects having an objectively unique meaning characterised by positivist conceptualisations.

As the value cocreation paradigm shift occurred, the same basic concept of the market has changed. Here, positivism and modernism was replaced by constructivism and postmodernism, and customers were individuals with perspectives that differed. More importantly, they communicated with each other, therefore exposing their relative perspectives to critical exposure. Here, value is still created, but exposure to interactive processes meant that value creation might be temporary and unstable.

Under an agency theory lens, the market is now conceived as a forum where conversations are among agencies (providers and customers). According to this view, the market is regarded as a "sign system", an arena where providers and customers together cocreate value through significatory systems [67] driven by social constructs and individual values in symbolically oriented negotiations. From an agency theory perspective, the market is seen as a customer plural interactive and complex locality from which value emerges through processes of communication. This is not just a set of singular values that are owned by customers and can be aggregated so that an average value is created. It is rather a complex process of value cocreation that emerges from dynamic communicative interactions that occur between customers.

As a consequence of the abovementioned concepts, the two classes of customers and providers can each be considered as agencies. Applying the theory from [11], agencies are "viable living systems" that have the property of durability through adaptation. Since our interest lies in the market context, it must be said that agencies also value products. In traditional models, value creation is an individual attribute, but in an interactive context that draws on social networking, it turns into value cocreation through the development of complex processes (Figure 1). Each viable living system may have within 
it a viable system defined by its unique context. In this case, the market is an adaptive viable system populated by customers and producers who are also adaptive viable systems. In the same way as customers and producers are together generators of value creation, the market arena is a generator of value cocreation that centres on identifiable products. In addition to customers and producers in Figure 1, there is also the class of objects of attention, called products, which are symbolically connected to behaviour through associated meaning.

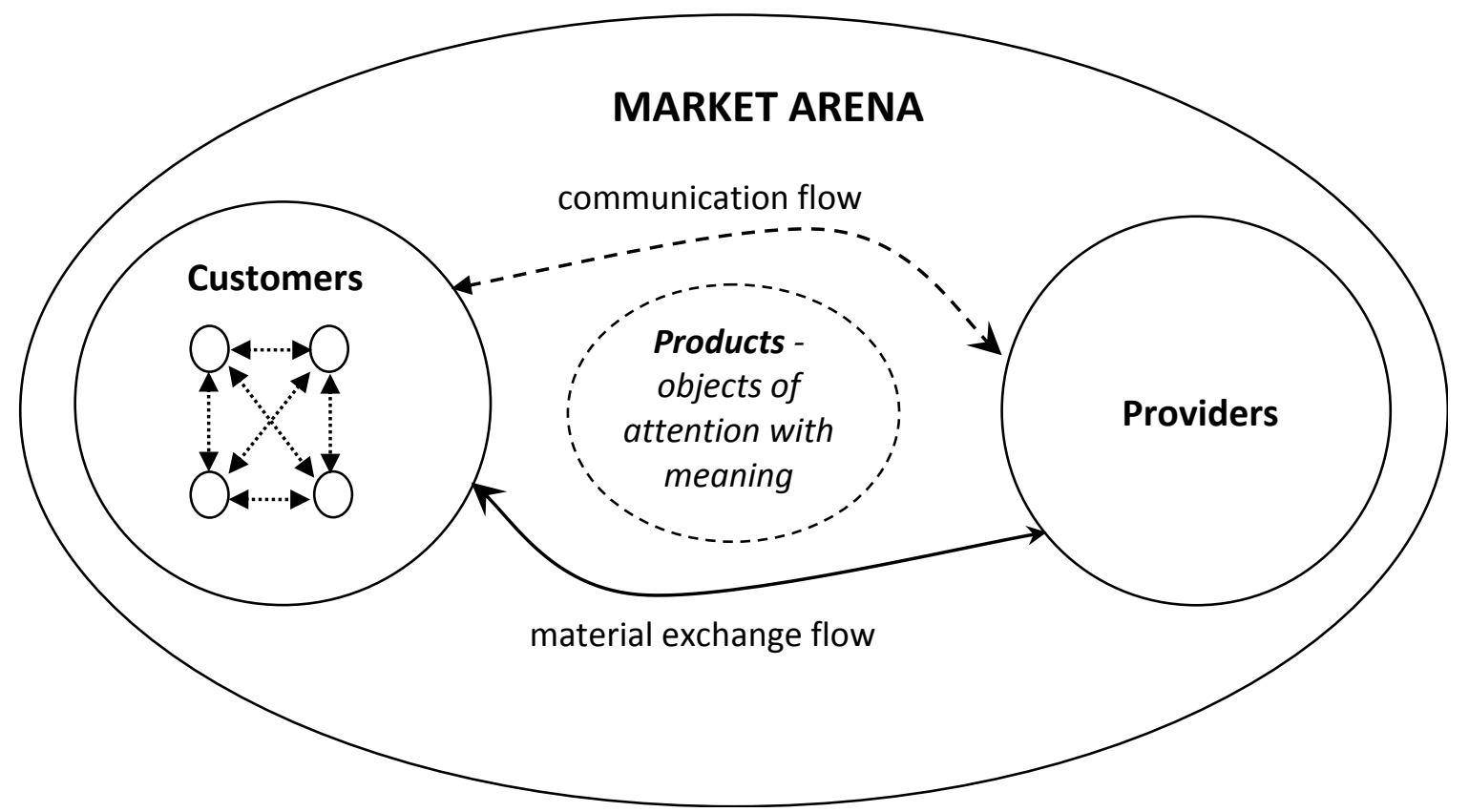

Figure 1. Classes of Agency in a market arena interacting to cocreate value, with customers and producers individually interacting to cocreate common product based meaning.

As we have seen, value cocreation happens in the market arena as a result of interactions. It requires that the marketing arena is seen as an operative system populated by a set of loyal customers and others who are not loyal, and loyalty has cultural attributes [68], implying that the market arena of Figure 1 can be seen as an operative system of a market agency.

The dynamic nature of the market enables one to see it as a space of interactive processes in which individual value creation shifts to value cocreation, a conceptualisation in marketing that constitutes a paradigm shift. However, unlike the nature of value creation, value cocreation is not a linear accumulation that can be represented through statistical averages, but rather embraces an underlying complex process of lifeworld social interaction from which the emergence of a viable sociocultural collective may occur [69]. Here, individuals in a market socially interact over value, and as they continue to do so under conditions of uncertainty [70,71], their interactions may reinforce each other resulting in the emergence of something quite new.

To explain this further, we can refer to Allen [72] who tells us that individuals engage in processes of communication through social media, and in so doing increasingly take their cues from one another and their social communities, as opposed to institutional sources such as corporate providers [73]. These cues are reflections of symbolic imagery that are negotiated through lifeworld processes. This recursive and dynamic negotiation brings the "emergence" of the value cocreation process that may then be taken to represent a collective process even though it originates as a collection of individual ones. It is a similar process to that which occurs as individuals in an orchestra start to tune up their instruments, and through the adoption of conscious or subconscious cues that appear to occur as a process of transference, somehow the orchestra shifts discontinuously from a set of individual fragments of musical narrative (called antenarratives, [74]) to a coherent musical narrative. 
"Cocreated" value depends on how agencies in the market arena jointly create the market offerings as shared symbolic meanings of the cocreation consumption experience $[5,75]$. Therefore, the value of a specific product is the result of a customer experience deriving from the implicit negotiation between each customer and the provider of that product; this is implied in the Business to Consumer (B2C) market negotiation with thousands or millions of customers [66]. As will be seen in due course, the formation of the meaning of a product is also the result of interactions and communications among customers that may form groups around products that have a higher symbolic meaning. From this perspective, value does not have a universal significance but is a relative and complex perception of sense that assumes different forms that depend on agency perspectives, time, and context [76].

This negotiation is a process whereby a plurality of agencies strive to reach agreement for the cocreation of value, thereby dealing with distinctions and differences across an individual's proprietary ideas of value. However, unlike negotiation strategies, there is no "objective" negotiator, only common exchanges of meaning that occur throughout the lifeworld that facilitate consensus [77]. This view resonates with Habermas' $[77,78]$ theory of communicative action, according to which, actors in a social setting seek to reach common understanding and to coordinate actions by reasoned argument, consensus, and cooperation rather than through strategic action occurring strictly in pursuit of their own goals.

Hence, cocreation overcomes the mere material production of goods by shifting to the production of sense and meaning, this resulting from the interactions among multiple agents and their access to resources, and develops through symbols and the emergence of a common language to create structural coupling [32], a term that indicates that agencies historically influence each other, and direct interactions [77]. This lifeworld communication process may be considered to underpin the imperatives for behaviour in a market agency. In the market context lifeworld, as a concept elaborated on by Shultz and Luckmann [79] and Habermas [77], this occurs between agencies which maintain their proprietary local worldviews and communicate with intention over a (product) theme. In so doing they create messages that are knowledge laden, and which become part of a value cocreation negotiation process. Since the lifeworld comes into being only through a plural composition of worldviews, there is some use in exploring the nature of the latter a little further within the context of the former. Worldviews are independent local topological spaces that interact in the lifeworld through communication processes that involve the exchange of messages. Each locality has an epistemological content that enables it to maintain a capacity to develop meaning, and through its interaction, to create mutual local understanding that offers a potential for the formation of value cocreation. This constitutes a relativity as meaning is migrated across agencies within the lifeworld, a process involving uncertainty with respect to collective meaning. Yolles [18] explains that this uncertainty can only be reduced through processes of social feedback.

The consequence of these interactions for value cocreation is not given by the "value-in-use" of an uncontroversial 'thing', but by the complex meanings created by recurrent and dynamic communication loops [35] that are part of the marketing lifeworld.

\section{Discussion and Conclusions}

This theoretical paper has aimed at clarifying the new dynamics of the market and the complexity of the value cocreation process. The shift in the conceptualisation relating to customer, market, and product has been analysed through an agency theoretical framework.

We have created a narrative to explain how, from the perspective of agency theory and the principles of social cybernetics that it embraces, that the market can be conceived as the physical or virtual arena where communications about products produce their meaning and symbolic value (eigenforms). This was possible because the role of the customer has changed and in today's market it is an active role as an agency instead of as a mere object of attention as it was in the traditional marketing paradigm. We also illustrated how agency theory allows us to better understand the information flows 
generating eigenvalues $\rightarrow$ eigenvectors $\rightarrow$ eigenbehaviors $\rightarrow$ eigenforms and understand the nature of the value creation process.

In particular, we focused on the shift of greatest relevance for marketing managers: the value cocreation shift. While a linear model would see the creation of value in the market as an aggregate sum of all the individual value creations, thus forming a value cocreation, this is an inadequate view of what is actually happening in the complex social environment. Rather, social communication occurs in a lifeworld in which meanings are relativistically interchanged between agencies. Due to this constructivist idea of relativity, there may be some degree of transformation in those meanings so that each agency in the lifeworld associated with a given class of product embraces proprietary meanings that are not directly comparable. However, through processes of negotiations concerned with meaning that that reflect on lifeworld processes [77,78], symbolic meanings may emerge that centre on particular products. It is this that explains value cocreation.

According to the agency framework presented in this study, the shift from value creation to value cocreation can be explained by the change in the "object of attention" in the market arena (See Figure 1). For the traditional framework of value creation, the agency that instigates the interaction in the market arena is the provider and the object of attention is the customer that has to be convinced of the value in use of a given product through passive exposure to commercial communication, thus creating value from the exchange of value in use with cash flow.

Even though for the provider the ultimate goal is always the same as in the traditional framework (earning money from the customer), the underlying concept and the dynamics used to obtain this is different in value cocreation. The object of attention is now the product as a token and its value is not given by the mere and "rational" value in use, but by its representative value that is "non-rationally" attributed by the customer through the described value formation process made of cyclical information flows generating eigenvalues, eigenvectors, eigenbehaviors, and ultimately the eigenform as the perceived product and its value for the customer.

In the agency theory adopted, the development of value cocreation was illustrated. This has provided insight into the dynamics of the process of value cocreation by decoding it into the various interacting parts underlying its formative dynamics.

We are aware that this paper is a theoretical paper; future papers are likely to be concerned with more managerial aspects. Regarding the managerial implication of this framework, the analysis provided here may be seen as a starting point to develop more practical models of action that may allow firms to adopt strategies and policies to foster value cocreation and grasp possible evolutionary directions of the value cocreation process. This initial approach to the examination of the complex market dynamics and to the process of value cocreation provides a route to more detailed and pragmatic analyses. It is likely that further research in this topic grounded in agency theory may produce practical models to help firms find tools to better steer (not control) the value cocreation process, which then adopts its own dynamic. In particular, we are already conducting further research to analyse the process of sense making and meaning negotiation in consumption communities.

Author Contributions: Even though the article is the joint work of both authors, who both contributed to each paragraph, to conform with Italian regulation on academic publishing, we may attribute the contribution of each author as follows (based on the prominence of the role of the author in the section): Sections 1, 3.2, 3.3 and 4 can be attributed to Gandolfo Dominici; while Sections 2, 3.1 and 3.4 can be attributed to Maurice Yolles.

Conflicts of Interest: The authors declare no conflict of interest.

\section{References}

1. Brown, S. Marketing as Multiplex: Screening Postmodernism. Eur. J. Mark. 1994, 28, 27-51. [CrossRef]

2. Christensen, L.T.; Torp, S.A.; Firat, F. Integrated marketing communication and postmodernity: An odd couple? Corp. Commun. Int. J. 2005, 10, 156-167. [CrossRef]

3. Cova, B.; Cova, V. Tribal marketing: The tribalisation of society and its impact on the conduct of marketing. Eur. J. Mark. 2002, 36, 595-620. [CrossRef] 
4. Goneos-Malka, A.; Grobler, A.; Strasheim, A. Suggesting new communication tactics using digital media to optimise postmodern traits in marketing. S. Afr. J. Commun. Theory Res. 2013, 39, 122-143. [CrossRef]

5. Firat, A.F.; Dholakia, N. Theoretical and philosophical implications of postmodern debates some challenges to modern marketing. Mark. Theory 2006, 6, 123-162. [CrossRef]

6. Grönroos, C. Service logic revisited: Who creates value? And who co-creates? Eur. Bus. Rev. 2008, 20, 298-314. [CrossRef]

7. Grönroos, C.; Strandvik, T.; Heinonen, K. Value Co-Creation: Critical Reflections. In The Nordic School-Service Marketing and Management for the Future; Gummerus, J., von Koskull, C., Eds.; CERS, Hanken School of Economics: Helsinki, Finland, 2015; pp. 69-81.

8. Vancouver, J.B. Living systems theory as a paradigm for organizational behavior: Understanding humans, organizations, and social processes. Behav. Sci. 1996, 41, 165-204. [CrossRef] [PubMed]

9. Maturana, H.R.; Varela, F.J. Autopoiesis and Cognition; Boston Studies in the Philosophy of Science: Boston, MA, USA, 1979.

10. Schwarz, E. A Metamodel to interpret the Emergence, Evolution and Functioning of Viable Natural Systems. In Proceedings of the European Meeting on Cybernetics and Systems Research, Vienna, Austria, 5-8 April 1994; Trappl, R., Ed.; World Scientific: Singapore, 1994; pp. 1579-1586.

11. Schwarz, E. Towards a Holistic Cybernetics: From Science through Epistemology to Being. Cybern. Hum. Knowing. 1997, 4, 17-50.

12. Schwarz, E. Anticipating systems: An application to the possible futures of contemporary society. In Proceedings of the Invited paper at CAYS'2001, Fifth International Conference on Computing Anticipatory Systems, Liege, Belgium, 13-18 August 2001.

13. Bacharach, S.B. Organisational Theories: Some criteria for evaluation. Acad. Manag. Rev. 1989, 14, 496-515.

14. Whetten, D.A. What Constitutes a Theoretical Contribution. Acad. Manag. Rev. 1989, 14, 490-495. [CrossRef]

15. Bandura, A. Social Foundations of Thought and Action: A Social Cognitive Theory; Prentice-Hall: Englewood Cliffs, NJ, USA, 1986.

16. Haken, H.; Juval, P. Information and Self organization: A Unifying Approach and Application. Entropy 2016, $197,1-57$.

17. Mingers, J. Self-Producing Systems; Plenum Press: New York, NY, USA; London, UK, 1995.

18. Yolles, M.I. Organizations as Complex Systems: An Introduction to Knowledge Cybernetics; Volume Two of the Series Managing the Complex; Information Age Publishing: Greenwich, CT, USA, 2006.

19. Piaget, J. The Psychology of Intelligence; Harcourt and Brace: New York, NY, USA, 1950.

20. Beer, S. The Heart of Enterprise; John Wiley \& Sons: Chichester, UK, 1979.

21. Yoon, K.L. Political Culture of Individualism and Collectivism. Ph.D. Thesis, University of Michigan, Ann Arbor, MI, USA, 2010.

22. Yolles, M.I.; Fink, G. A General theory of generic modelling and paradigm shifts: Part 1-The fundamentals. Kybernetes 2010, 44, 283-298. [CrossRef]

23. Yolles, M.I.; Fink, G. A General theory of generic modelling and paradigm shifts: Part 2. Cybernetics orders. Kybernetes 2015, 44, 299-310. [CrossRef]

24. Yolles, M.I.; Fink, G. A General theory of generic modelling and paradigm shifts: Part 3. The extension. Kybernetes 2015, 44, 311-328. [CrossRef]

25. Miller, J.G. Living Systems; McGraw-Hill: New York, NY, USA, 1978.

26. Rampen, W. My Personal Definition of Business with Customer Value Co-Creation, Customer Think. 2009.

27. Levy, S. Symbols for sale. In Harvard Business Review; Sage Publications: New York, NY, USA, 1959; Volume 37, pp. 117-124.

28. Levy, S. Dreams, Fairy Tales, Animals and Cars. Psychol. Mark. 1985, 2, 67-81. [CrossRef]

29. McCracken, G. Culture and Consumption: A Theoretical Account of the Structure and Movement of the Cultural Meaning of Consumer Goods. J. Consum. Res. 1986, 13, 71-84. [CrossRef]

30. Muniz, A.M. Brand community and the negotiation of brand meaning. In Advances in Consumer Research, Volume 24, ed.; Brucks, M., MacInnis, D.J., Eds.; Association for Consumer Research: Provo, UT, USA, 1997; pp. 308-309.

31. Broderick, A.; MacLaran, P.; Ma, P.Y. Brand Meaning Negotiation and the Role of the Online Community: A Mini Case Study. J. Custom. Behav. 2003, 2, 75-103. [CrossRef] 
32. Dominici, G.; Basile, G.; Palumbo, F. Viable systems approach and consumer culture theory: A conceptual framework. J. Organ. Transform. Soc. Change 2013, 10, 262-285. [CrossRef]

33. Espejo, R.; Dominici, G. Cybernetics of Value Cocreation for Product Development. Syst. Res. Behav. Sci. 2016, in press. [CrossRef]

34. Toffler, A. The Third Wave; Bantam: New York, NY, USA, 1980.

35. Packard, V. The Hidden Persuaders; David McKay Company: New York, NY, USA, 1957.

36. Hackley, C.; Tiwsakul, R.A.; Preuss, L. An ethical evaluation of product placement: A deceptive practice? Bus. Eth. Eur. Rev. 2008, 17, 109-120. [CrossRef]

37. Normann, R.; Ramirez, R. Designing Interactive Strategy. Harvard Business Review. 1993. Available online: https:/ /hbr.org/1993/07/designing-interactive-strategy (accessed on 8 January 2016).

38. Vargo, S.L.; Lusch, R.F. Evolving to a new dominant logic for marketing. J. Mark. 2004, 68, 1-17. [CrossRef]

39. Vargo, S.L.; Lusch, R.F. Service-dominant logic: Continuing the evolution. J. Acad. Mark. Sci. 2008, 36, 1-10. [CrossRef]

40. Lusch, R.F.; Vargo, S.L. Service Dominant Logic: Premises, Perspectives, Possibilities; Cambridge University Press: Cambridge, UK, 2014.

41. Grönroos, C. Adopting a service logic for marketing. Mark. Theory 2006, 6, 317-333. [CrossRef]

42. Woodruff, R.B.; Flint, D.J. Marketing's service dominant logic and customer value. In The Service-Dominant Logic of Marketing: Dialog, Debate and Direction; Lusch, R.F., Vargo, S.L., Eds.; M.E. Sharpe: Armonk, NY, USA, 2006; pp. 183-195.

43. Kalaignanam, K.; Varadarajan, R. Customers as coproducers: Implications for marketing strategy effectiveness and marketing operations efficiency. In The Service Dominant Logic of Marketing: Dialog, Debate and Direction; Lusch, R.F., Vargo, S.L., Eds.; M.E. Sharpe: Armonk, NY, USA, 2006; pp. 166-179.

44. Etgar, M. A descriptive model of the consumer co-production process. J. Acad. Mark. Sci. 2008, 36, 97-108. [CrossRef]

45. Kotler, P.T.; Armstrong, G. Principles of Marketing: Global Edition; Pearson Education: New York, NY, USA, 2009.

46. Kauffman, L.H. Eigenform. In Proceedings of the 51st Annual Meeting of the ISSS-2007, Tokyo, Japan, 5-10 August 2007; Available online: www.isss.org/index.php/proceedings51st/article/view/811/295 (accessed on 7 Janaury 2016).

47. Bruner, J. Actual Minds, Possible Worlds; Harvard University Press: Boston, MA, USA, 1987.

48. Cusumano, M.A.; Mylonadis, Y.; Rosenbloom, R.S. Strategic Maneuvering and Mass-Market Dynamics: The Triumph of VHS over Beta. Bus. Hist. Rev. 1992, 66, 51-94. [CrossRef]

49. Schembri, S. Reframing brand experience: The experiential meaning of Harley-Davidson. J. Bus. Res. 2009, 62, 1299-1310. [CrossRef]

50. McCormick, J. Why Harley-Davidson May Not Be the Perfect Ride for Scott Walker. 2015. Available online: http:/ /www.bloomberg.com/politics/articles/2015-08-13/harley-davidson-may-not-bethe-perfect-ride-for-scott-walker (accessed on 12 April 2016).

51. Schouten, J.W.; McAlexander, J.H. Subcultures of Consumption: An Ethnography of the New Bikers. J. Consum. Res. 1995, 22, 43-61. [CrossRef]

52. Johnson, M. Powerful Symmetries and Eigenforms. 2011. Available online: http://dailyimprovisation. blogspot.co.uk/2011/11/powerful-symmetries-and-eigenforms.html (accessed on 11 April 2016).

53. Von Foerster, H. Observing Systems; The Systems Inquiry Series; Intersystems Publications: Salina, CA, USA, 1981.

54. Kauffman, L.H. Eigenform. Kybernetes 2005, 34, 129-150. [CrossRef]

55. Krippendorff, K. Cybernetics'sreflexive turns. Cybern. Hum. Knowing 2008, 15, 173-184.

56. Achterbergh, J.; Vriens, D. Organizations. In Social Systems Conducting Experiments, 2nd ed.; Springer: Heidelberg, Germany, 2010.

57. Varela, F.J.; Thompson, E.; Rosch, E. The Embodied Mind; MIT Press: Cambridge, MA, USA, 1993.

58. Latour, B. Reassembling the social. In An Introduction to Actor-Network-Theory; Oxford University Press: New York, NY, USA, 2005.

59. Lebra, T.S. Japanese Patterns of Behaviour; University of Hawaii Press: Honolulu, HI, USA, 1976.

60. De Vries, M.F.R. The entrepreneurial personality: A person at the crossroads. J. Manag. Stud. 1977, 14, 34-57. [CrossRef] 
61. Bilsky, W.; Schwartz, S.H. Values and personality. Eur. J. Personal. 1994, 8, 163-181. [CrossRef]

62. Bermúdez, J. Personality and health-protective behaviour. Eur. J. Personal. 1999, 13, 83-103. [CrossRef]

63. Yolles, M.I.; Fink, G. Personality, pathology and mindsets: Part 1-Agency, personality and mindscapes. Kybernetes 2014, 43, 92-112. [CrossRef]

64. Yolles, M.I.; Fink, G. Personality, pathology and mindsets: Part 2-Cultural traits and enantiomers. Kybernetes 2014, 43, 113-134. [CrossRef]

65. Yolles, M.I.; Fink, G. Personality, pathology and mindsets: Part 3-Pathologies and corruption. Kybernetes 2014, 43, 135-143. [CrossRef]

66. Prahalad, C.K.; Ramaswamy, V. Co-creation experiences: The next practice in value creation. J. Interact. Mark. 2004, 18, 5-14. [CrossRef]

67. Venkatesh, A.; Penaloza, L.; Firat, A.F. The Market as a Sign System and the Logic of the Market. In The Service-Dominant Logic of Marketing: Dialog, Debate and Directions; Lusch, R.F., Vargo, S.L., Eds.; M.E. Sharpe: Armonk, NY, USA; London, UK, 2006; pp. 251-265.

68. Eagle, N.; Pentland, A.S. Eigenbehaviors: Identifying structure in routine. In Behavioral Ecology and Sociobiology; Springer: Heidelberg, Germany, 2009; Volume 63, pp. 1057-1066.

69. Thietart, R.A.; Forgues, B. Chaos theory and organization. Organ. Sci. 1995, 6, 19-31. [CrossRef]

70. Plowman, D.A.; Baker, L.T.; Beck, T.E.; Kulkarni, M.; Solansky, S.T.; Travis, D.V. Radical change accidentally: The emergence and amplification of small change. Acad. Manag. J. 2007, 50, 515-543. [CrossRef]

71. Yolles, M.; Fink, G. The changing organisation: An agency modelling approach. Int. J. Mark. Bus. Syst. 2015, 1, 217-243. [CrossRef]

72. Allen, S.; Deragon, J.T.; Orem, M.G.; Smith, C.F. The Knowledge Factors. The Emergence of the Relationship Economy: The New Order of Things to Come. Link to your worls LLC, Cupertino, CA, USA, 2008. Available online: http://theengagingbrand.typepad.com/the_engaging_brand_/files/RelationshipEconomy-eBookv. 04.pdf (accessed on 10 April 2016).

73. Charron, C.; Favier, J.; Li, C. Social Computing: How Networks Erode Institutional Power, and What to Do about It; Forrester Customer Report. Forrester Research Inc., 2006. Available online: http:/ /www.cisco.com/web/ offer/socialcomputing/SocialComputingBigIdea.pdf (accessed on 18 April 2016).

74. Boje, D.M. Narrative Methods for Organisational and Communication Research; Sage: London, UK, 2001.

75. Pongsakornrungsilp, S.; Schroeder, J.E. Understanding value co-creation in a co-consuming brand community. Mark. Theory 2011, 11, 303-324. [CrossRef]

76. Holbrook, M.B. Consumption experience, customer value, and subjective personal introspection: An illustrative photographic essay. J. Bus. Res. 2006, 59, 714-725. [CrossRef]

77. Habermas, J. The Theory of Communicative Action. In Reason and the Rationalization of Society; Polity Press: Cambridge, UK, 1984; Volume 1.

78. Habermas, J. The Theory of Communicative Action. In Lifeworld and System: A Critique of Functionalist Reason; Polity Press: Cambridge, UK, 1987; Volume 2.

79. Schultz, A.; Luckmann, T. The Structures of the Lifeworld; Heinamann: London, UK, 1974.

(c) 2016 by the authors; licensee MDPI, Basel, Switzerland. This article is an open access article distributed under the terms and conditions of the Creative Commons Attribution (CC-BY) license (http://creativecommons.org/licenses/by/4.0/). 